RSC Advances. 6 (89): pp. 86575-86585, 2016.

\title{
Amino-functionalized mesoporous silica based polyethersulfone- polyvinylpyrrolidone composite membranes for elevated temperature proton exchange membrane fuel cells
}

Jin Zhang ${ }^{\mathrm{a}}$, Shanfu Lu $u^{\mathrm{b}}$, Haijin Zhu ${ }^{\mathrm{c}}$, Kongfa Chen ${ }^{\mathrm{a}}$, Yan Xiang ${ }^{\mathrm{b}}$, Jian Liu ${ }^{\mathrm{a}}$, Maria Forsyth San Ping Jiang*a

${ }^{a}$ Fuels and Energy Technology Institute \& Department of Chemical Engineering, Curtin University, Perth, WA6102, Australia

${ }^{b}$ Beikjing Key Laboratory for Bio-inspired Energy Materials and Devices, School of Space and Environment, Beihang University, Beijing 100191, P.R.China

${ }^{c}$ Institute for Frontier Materials, Deakin University, Geelong, VIC 3220, Australia.

* Corresponding author

Email: s.jiang@curtin.edu.au (Prof. San Ping Jiang); Tel: + 6192669804 
RSC Advances. 6 (89): pp. 86575-86585, 2016.

\section{Abstract}

It is important to find alternative membranes to the state-of-the-art polybenzimidazole based high temperature proton exchange membranes with high proton conductivity at elevated temperature but with simple synthesis procedures. In this work, inorganic-organic nanostructured hybrid membranes are developed based on polyethersuflonepolyvinylpyrrolidone (PES-PVP) polymeric matrix with hollow mesoporous silica (HMS), amino-functionalized hollow mesoporous silica ( $\mathrm{NH}_{2}-\mathrm{HMS}$ ) and amino-functionalized mesoporous silica ( $\mathrm{NH}_{2}$-meso-silica). The composite membranes show a significant increase in proton conductivity and a decrease in the activation energy for proton diffusion in comparison with the phosphoric acid $\left(\mathrm{H}_{3} \mathrm{PO}_{4}\right.$, PA) doped PES-PVP membrane. And the composite membrane with $\mathrm{NH}_{2}$-HMS shows the best performance under conditions in this study, achieving the highest proton conductivity of $1.52 \times 10^{-1} \mathrm{~S} \mathrm{~cm}^{-1}$ and highest peak power density of $480 \mathrm{~mW} \mathrm{~cm}^{-2}$ at $180{ }^{\circ} \mathrm{C}$ under the anhydrous condition, which is $92.7 \%$ higher than that of the PA doped PES-PVP membrane at the identical condition. Such enhancement results from the facilitated proton transportation in the ordered mesoporous channels via the hydrogen bond between the $-\mathrm{NH}_{2}$ groups and $\mathrm{H}_{3} \mathrm{PO}_{4}$. The high water retention capability of silica materials with hollow structure also contributes to the decrease of the activation of proton diffusion. Consequently, the results show promising potential of the $\mathrm{NH}_{2}-\mathrm{HMS}$ based PES-PVP composite membrane for the elevated temperature proton exchange membrane fuel cells.

Keywords: proton exchange membrane fuel cells; hollow mesoporous silica; aminofunctionalization; PES-PVP composite membrane; high temperature fuel cells. 
RSC Advances. 6 (89): pp. 86575-86585, 2016.

\section{Introduction}

The proton exchange membrane fuel cells (PEMFCs) show superiorities of fast start-up and shut-down cycle in comparison with the other types of fuel cells. It is, therefore, considered to be one of the most promising power generation technologies for applications ranging from portable electronic devices, transportation vehicles to power stations. On the other hand, the low operating temperature $\left(<80{ }^{\circ} \mathrm{C}\right)$ results in complex water management ${ }^{1}$ and $\mathrm{CO}$ poisoning to $\mathrm{Pt}$ catalyst from fuel gases ${ }^{2}$. However, the problems are mostly diminished at elevated temperatures $\left(100-200{ }^{\circ} \mathrm{C}\right)$ for PEMFCs with improved catalytic kinetics, high fuel impurity tolerance as well as simplified water management systems ${ }^{3}$. Different from hydrated $\mathrm{H}^{+}$ions as proton conductor for PEMFCs operated at low temperatures, phosphoric acid (PA) ${ }^{4}$, ionic liquids ${ }^{5}$ and heterocyclic compounds including imidazole $^{6}$ and triazole ${ }^{7}$ have been investigated as alternative proton conductors in proton exchange membranes at elevated temperatures. Those alternative proton conductors allow for the reduced dependence on humidity and showed high proton conductivity at elevated temperatures. Among them, PA is probably one of the most promising proton conductors in that connection and has been extensively applied in basic polymer-based PEMs, such as polybenzimidazole $(\mathrm{PBI})^{8-10}$ and pyridine containing aromatic polyethers ${ }^{11}$. PA-doped PBI membrane (PA/PBI) is the state-of-the-art PEM operated at elevated temperatures, showing the high proton conductivity at low relative humidity $(\mathrm{RH})$ as well as good thermal and oxidative stability $^{12}$. However, full-scale applications of PBI based PEMs are limited by the relatively complicated fabrication procedures of the PBI polymeric material.

Recently, other basic polymer membranes with simple fabrication procedures were developed as alternative elevated temperature PEMs, such as polyvinylpyrrolidone (PVP), 
RSC Advances. 6 (89): pp. 86575-86585, 2016.

and poly(4-vinylpyridine). Lu et al. synthesized the PA-doped polymer composite membrane by blending PVP with polyvinylidene fluoride $(\mathrm{PVDF})^{13}$ or poly(ether sulfone $)^{14}$. These membranes showed the excellent thermal stability and high proton conductivity at temperatures up to $180{ }^{\circ} \mathrm{C}^{14}$. Generally, for the basic polymer based composite membranes, the first phase supports the mechanical stability of the composite membrane such as PVDF and PES, while the second phase plays the role as proton transportation network with liquidlike dynamics in nanoscale channels or pores formed in miscible blends, such as PVP. ${ }^{15}$ However, there is a trade-off between the proton conductivity and mechanical strength in the composite membrane, which is closely related to the content of PVP. That is, reducing the PVP content would decrease the proton conductivity of the composite membrane with the increased mechanical strength of the membranes. ${ }^{14}$

Nevertheless, the proton conductivity of composite membranes can be improved by incorporating functionalized nano- or mesoporous silica materials such as phosphorylated hollow mesoporous silica (HMS) submicro spheres ${ }^{16}$, PBI-functionalized silica nanoparticles ${ }^{17}$, ionic liquid-functionalized mesoporous silica ${ }^{18}$, phosphotungstic acid functionalized mesoporous silica ${ }^{19}$, and proton conducting groups functionalized mesoporous silica $^{20}$. Among them, functionalized HMS shows the high water uptake due to a large amount of lumen and facilitated proton transportation in the functionalized mesoporous silica channels. Jiang et al. found that the proton conductivity of recast Nafion membrane at low relativity humidity $(\mathrm{RH})$ and $80{ }^{\circ} \mathrm{C}$ was improved 10 times after the addition of functionalized HMS with sulfonic acid, phosphoric acid and carboxylic acid groups ${ }^{21}$. Moreover, the phosphorylated HMS embedded chitosan membranes showed the high proton conductivity both at $100 \%$ and $40 \% \mathrm{RH}$ in comparison with the pristine chitosan membranes ${ }^{16}$. In addition, an enhanced interfacial interaction and control over the interface can be achieved by grafting amino-groups on silica surface ${ }^{22}$. The amine-tailored silica 
RSC Advances. 6 (89): pp. 86575-86585, 2016.

material improved the interfacial compatibility between the PBI membrane and silica particles by the hydrogen bonding interaction between PBI and amino-functionalized silica materials $^{23}$. It has been reported that self-assembled amino-functionalized silica particle clusters enhance the mechanical and thermal stability of the PBI matrix, and the PA uptake as well as the proton conductivity ${ }^{24}$.

Herein, a PES-PVP membrane with a relatively low PVP content was employed as polymer matrix. Hollow mesoporous silica, amino-functionalized hollow mesoporous silica ( $\mathrm{NH}_{2}$-HMS) and amino-functionalized mesoporous silica ( $\mathrm{NH}_{2}$-meso-silica) were incorporated into the polymer matrix to form nanostructured inorganic-organic composite membranes. The present work focused on the effects of the hollow structure and the aminofunctional groups of silica fillers on the properties of the composite membranes. More specifically, the interfacial interaction of the silica inorganic fillers and the polymer matrix was investigated in details. More importantly, the proton conductivity and cell performance of the composite membrane were carefully investigated and the functions of silica fillers were proposed. Besides, the durability of the fuel cells based on the composite membrane as well as the pristine PES-PVP membrane was also investigated to reveal the feasibility of the nanostructure inorganic-organic hybrid membrane in fuel cells.

\section{Experimental}

\subsection{Mesoporous silica fabrication}

Mesoporous silica (meso-silica) were prepared by mixing $2.5 \mathrm{~g}$ Cetyltrimethylammonium bromide (CTAB, Sigma-Aldrich) and 15.2 g ammonia solution (28 wt\%, Sigma-Aldrich) in $50 \mathrm{~mL}$ Milli-Q water and $75 \mathrm{~mL}$ ethanol, followed by an addition of $5.0 \mathrm{~mL}$ Tetraethyl orthosilicate (TEOS, Sigma-Aldrich) and vigorous stirred at room temperature for $2 \mathrm{~h}$. The suspension was then centrifuged at $8000 \mathrm{rpm}$ for $10 \mathrm{~min}$, and the solid was washed twice by 
RSC Advances. 6 (89): pp. 86575-86585, 2016.

water and ethanol. The as-synthesized mesoporous silica particles were dried at $90{ }^{\circ} \mathrm{C}$ overnight, and then calcined in air at $550{ }^{\circ} \mathrm{C}$ for $6 \mathrm{~h}$ to remove the surfactant.

To synthesize HMS, silica sphere template was obtained by modified Stöber method ${ }^{25}$. Typically, $12 \mathrm{~mL}$ TEOS was added into a solution with $150 \mathrm{~mL}$ ethanol, $20 \mathrm{~mL}$ Milli-Q water and $6.3 \mathrm{~mL}$ ammonia solution (28 wt\%) and stirred at room temperature for $1 \mathrm{~h}$. After the centrifuge treatment, the solid silica spheres were ultrasonicated at $500 \mathrm{~mL}$ Milli-Q water and $150 \mathrm{~mL}$ ethanol for $0.5 \mathrm{~h}$. And the suspension was transferred into the CTAB solution with 3.0 g CTAB, $40 \mathrm{~mL}$ Milli-Q water, $20 \mathrm{~mL}$ ethanol, and $7.0 \mathrm{~mL}$ ammonia solution (28 wt\%). TEOS (4.5 mL) was added dropwise and stirred at room temperature overnight. Then the suspension was centrifuged at $8000 \mathrm{rpm}$ for $5 \mathrm{~min}$ and the obtained solid was redispersed at $500 \mathrm{~mL}$ Milli-Q water. After the addition of $10.5 \mathrm{~g}$ sodium carbonate $\left(\mathrm{Na}_{2} \mathrm{CO}_{3}\right)$, the suspension was etched at $60{ }^{\circ} \mathrm{C}$ for $12 \mathrm{~h}$. Finally, the hollow mesoporous silica powder was dried at $90{ }^{\circ} \mathrm{C}$ overnight, and the templates in the silica powders were removed by calcination in air at $550{ }^{\circ} \mathrm{C}$ for $6 \mathrm{~h}$.

\subsection{Amino-functionalization of silica materials}

Amino-functionalized mesoporous silica or HMS was prepared by dispersing $2.0 \mathrm{~g}$ silica powder in $80 \mathrm{~mL}$ toluene. The suspension was refluxed at $110{ }^{\circ} \mathrm{C}$ in an oil bath for $20 \mathrm{~h}$ under $\mathrm{N}_{2}$ protection after the addition of $3.0 \mathrm{~mL}$ (3-Aminopropyl)triethoxysilane (APTES, SigmaAldrich). The solid materials were finally washed by toluene for twice, and it was dried for future use. The amino-functionalized meso-silica and $\mathrm{HMS}$ were denoted as $\mathrm{NH}_{2}$-meso-silica and $\mathrm{NH}_{2}$-HMS.

\subsection{PES-PVP composite membrane}

Certain amount of silica materials were added into PES (Radel ${ }^{\circledR}$ A300, Solvay, Belgium) 
RSC Advances. 6 (89): pp. 86575-86585, 2016.

and PVP (PVP360, $\mathrm{M}_{\mathrm{w}}=360$ 000, Sigma-Aldrich) solution in N-methyl-2-pyrrolidone (NMP, Sigma-Aldrich) to form a slurry. The weight ratio for PVP to PES was 7:3, while the weight ratio of silica powders in the PES-PVP composite membrane was fixed at $2.0 \mathrm{wt} . \%$. The slurry was poured into a petri dish and dried in the oven at $80{ }^{\circ} \mathrm{C}$ for $48 \mathrm{~h}$. Membranes were peeled off from the petri dish and immersed in a 85 wt.\% $\mathrm{H}_{3} \mathrm{PO}_{4}$ solution (Lab Service, Australia) for one week for PA doping. The thickness of the composite membranes was in the range of $80-100 \mu \mathrm{m}$.

The PES-PVP composite membranes with $\mathrm{HMS}, \mathrm{NH}_{2}-\mathrm{HMS}$ and $\mathrm{NH}_{2}$-meso-silica were denoted as PES-PVP-H, PES-PVP-NH, and PES-PVP-NS, respectively, while the corresponding PA-doped PES-PVP composite membranes were denoted as PA/PES-PVP-H, PA/PES-PVP-NH, and PA/PES-PVP-NS, respectively.

\subsection{Characterizations}

Small-angle X-ray scattering (SAXS) profile was recorded on Australian synchrotron SAXS beamline with camera length of $650 \mathrm{~mm}$ and $3 \mathrm{GeV}$ electron storage ring, Melbourne, Australia. The $q$ range was $0.015-0.95 \AA^{-1}$. Mesoporous silica powders were confined in the holes of a flat plate sample holder which were covered with Kapton tape, while PES-PVP composite membranes were placed on the surface of the plate. The sample plate was then placed on the beamline. Transmission electron microscopy (TEM) was used to characterize the morphology of mesoporous silica powders by depositing of the suspension on a carbon grid via electron microscopy (JEOL JEM-2100F) at accelerating voltage of $120 \mathrm{kV}$. Q500 (TA instrument) Thermogravimetric analyser (TGA) was employed to investigate the thermal property of the silica materials and PES-PVP composite membranes from room temperature to $700{ }^{\circ} \mathrm{C}$ with heat ramp of $10^{\circ} \mathrm{C} \mathrm{min}^{-1}$ under air flow of $50 \mathrm{~mL} \mathrm{~min}{ }^{-1}$. Nitrogen adsorption isotherms, Brunauer-Emmett-Teller (BET) specific surface areas $\left(S_{\mathrm{BET}}\right)$ and porosity of the 
RSC Advances. 6 (89): pp. 86575-86585, 2016.

samples were measured at $-196{ }^{\circ} \mathrm{C}$ (liquid nitrogen) using Micromeritics ASAP 2020 gas adsorption apparatus. Before adsorption measurement the samples were degassed at $80{ }^{\circ} \mathrm{C}$ overnight. Attenuated Total Reflectance Fourier Transform Infrared spectroscopy (ATRFTIR) (zinc selenide top plate, Perkin-Elmer spectrum 100) was employed to record the grafting of amino-groups on mesoporous silica materials, and interaction between the mesoporous silica materials and PES-PVP matrix. Nuclear magnetic resonance (NMR) spectra were measured at Bruker Avance III 500MHz widebore NMR spectrometer equipped with a $4 \mathrm{~mm}$ MAS probe. ${ }^{13} \mathrm{C} \mathrm{CP} / \mathrm{MAS}$ NMR was tested at $10 \mathrm{kHz}$ MAS, while ${ }^{29} \mathrm{Si}$ MAS NMR was tested at single pulse, $10 \mathrm{kHz}$ MAS. Small flip angle of 5 degree, 40s recycle delay. Scanning electron microscopy (SEM, Zeiss Neon 40EsB) was employed to characterize the morphology of PES-PVP composite membrane. The SEM samples were prepared by immersing the composite membranes in liquid nitrogen and then followed by breaking with forceps.

Pt/C catalysts (50\% Pt/C, Alfa Aesar, USA) were used for the anode and cathode. Pt/C catalyst layers on Toray $^{\circledR}$ TGP-H-060 carbon paper were hot pressed with PES-PVP composite membranes at $180{ }^{\circ} \mathrm{C}$ and $10 \mathrm{MPa}$ to form the membrane-electrode-assembly (MEA). The loading for Pt and PVP ionomers (PVP40, Mw = 40 000, Sigma-Aldrich) in both anode and cathode was 0.35 and $0.18 \mathrm{mg} \mathrm{cm}^{-2}$, respectively. Then the MEA was placed in a single-cell hardware (active area $4.0 \mathrm{~cm}^{-2}$ ) for the cell performance measurement using a Greenlight G20 fuel cell test station. $\mathrm{H}_{2}$ and $\mathrm{O}_{2}$ (dry gas) flow rates were 50 and $100 \mathrm{~mL}$ min ${ }^{-}$ ${ }^{1}$, respectively. The proton conductivity of PES-PVP based composite membranes was measured using electrochemical impedance spectroscopy technique at frequencies ranging from $100 \mathrm{KHz}$ to $10 \mathrm{~Hz}$. 
RSC Advances. 6 (89): pp. 86575-86585, 2016.

\section{Results and discussion}

\subsection{Formation of amino-functionalized mesoporous silica materials}

Fig. 1 shows the TEM micrographs of $\mathrm{HMS}, \mathrm{NH}_{2}-\mathrm{HMS}$ and $\mathrm{NH}_{2}$-meso-silica. For the fabrication of HMS, solid silica spheres with an average size of $260 \mathrm{~nm}$ derived from Stöber method $^{25}$ were covered by mesoporous silica shells with the surfactant of CTAB in the mesopores. When the core-shell particles were exposed to the $\mathrm{Na}_{2} \mathrm{CO}_{3}$ solution, the solid $\mathrm{SiO}_{2}$ core was selectively etched out while the shell remained intact with the oriented mesoporous structure with thickness of $60 \mathrm{~nm}$ (Fig. 1A). This is due to the fact that the silicate-CTAB mesoporous shell is more stable than the inner solid $\mathrm{SiO}_{2}$ core under the alkaline conditions. ${ }^{25}$ The pore channels in HMS were aligned perpendicularly to the surface of the spheres, as shown in Fig. 1B. After the post-grafting of amino-groups, the morphology of HMS was still intact with mesoporous shell and hollow structure (Fig.1C and D). Wormlike mesoporous channels directed from the centre to the edge of the spheres were observed for $\mathrm{NH}_{2}$-meso-silica, as shown in Fig.1E and F. The average particle size was $350 \mathrm{~nm}$.

\section{Table 1}

Physical properties of HMS, $\mathrm{NH}_{2}-\mathrm{HMS}$ and $\mathrm{NH}_{2}$-meso-silica.

\begin{tabular}{lllll}
\hline Samples & - $\mathrm{NH}_{2}$ content (wt.\%) & $\begin{array}{l}\text { BET surface area } \\
\left(\mathrm{m}^{2} \mathrm{~g}^{-1}\right)\end{array}$ & $\begin{array}{l}\text { Pore size } \\
(\mathrm{nm})\end{array}$ & $\begin{array}{l}\text { Pore volume } \\
\left(\mathrm{cm}^{3} \mathrm{~g}^{-1}\right)\end{array}$ \\
\hline HMS & - & 1275 & 2.9 & 1.03 \\
$\mathrm{NH}_{2}$-HMS & $9.8(1.69 \mathrm{mmol})$ & 1069 & 2.6 & 0.72 \\
$\mathrm{NH}_{2}$-meso-silica & $9.2(1.58 \mathrm{mmol})$ & 592 & 2.2 & 0.32 \\
\hline
\end{tabular}

Fig.2 shows $\mathrm{N}_{2}$ adsorption/desorption isotherms of mesoporous silica and aminofunctionalized mesoporous silica materials. The adsorption isotherms show type IV adsorption curves with $\mathrm{H} 2$ type hysteresis, characteristic of mesoporous materials ${ }^{26}$ (Fig. 2A). The BET surface area of HMS was $1275 \mathrm{~m}^{2} \mathrm{~g}^{-1}$. After the amino-functionalization, the surface area of $\mathrm{NH}_{2}$-HMS was reduced to $1069 \mathrm{~m}^{2} \mathrm{~g}^{-1}$, which is higher than $592 \mathrm{~m}^{2} \mathrm{~g}^{-1}$ for $\mathrm{NH}_{2}$-meso- 
RSC Advances. 6 (89): pp. 86575-86585, 2016.

silica. This may be due to the large lumen of $\mathrm{NH}_{2}-\mathrm{HMS}^{27}$. Moreover, the pore size of HMS decreased from 2.9 to $2.6 \mathrm{~nm}$ (Fig.2B), while the pore volume dropped from $1.03 \mathrm{~cm}^{3} \mathrm{~g}^{-1}$ for HMS to $0.72 \mathrm{~cm}^{3} \mathrm{~g}^{-1}$ after the amino-functionalization. The reduced pore size and pore volume indicate the successful grafting of $-\mathrm{NH}_{2}$ group on the surface of the mesoporous channels of $\mathrm{HMS}^{28}$ Based on the TGA analysis (Fig.2D), the content of amino-groups in $\mathrm{NH}_{2}$-HMS and $\mathrm{NH}_{2}$-meso-silica was 9.8 and $9.2 \%$, respectively, corresponding to 1.69 and 1.58 mmol. Physical properties of HMS, $\mathrm{NH}_{2}$-HMS and $\mathrm{NH}_{2}$-meso-silica are listed in Table 1.

The mesoporous structure of amino-functionalized mesoporous silica was confirmed by synchrotron small angle X-ray scattering, as shown in Fig. 2C. A broad peak was observed in the SAXS curve of HMS, indicating the oriented pore structure of the mesoporous silica materials. This is consistent with the observed ordered mesoporous shell structure in the TEM image, ${ }^{29}$ as shown in Fig.1. After grafting of $-\mathrm{NH}_{2}$ groups, the scattering peak increased to a high $q$ value, indicating the decrease of the pore size. On the other hand, $\mathrm{NH}_{2}$-meso-silica shows a sharp peak in comparison with HMS and $\mathrm{NH}_{2}$-HMS, suggesting a higher level of orientation of the mesoporous channels. ${ }^{30}$

The successful incorporating of amine group on HMS has been confirmed by solid-state ${ }^{13} \mathrm{C} \mathrm{CP} / \mathrm{MAS}$ NMR as shown in Fig.3A. The relevant carbon signals at 10, 22, $42 \mathrm{ppm}$ correspond to the carbon atoms at $-\mathrm{SiCH}_{2} \mathrm{CH}_{2} \mathrm{CH}_{2} \mathrm{NH}_{2}{ }^{31}$. In the ${ }^{29} \mathrm{Si}$ MAS NMR spectra of the hybrid particles, the peak signal at $-66 \mathrm{ppm}$ corresponds to the silicon connected to the amino group (Fig.3B), suggesting the condensation of APTES in HMS. It is noted that signals of incompletely hydrolysed silanes and templates which would appear around 59 and 14 ppm are absent in ${ }^{13} \mathrm{C} \mathrm{CP} / \mathrm{MAS} \mathrm{NMR}$, indicating the completely hydrolysed silanes and the template removal. ${ }^{32}$

The amino-functionalization of mesoporous silica was further confirmed by the ATR-FTIR 
RSC Advances. 6 (89): pp. 86575-86585, 2016.

characterization (Fig.3C). Taking HMS as examples, the most intensive band, centred at 1052 $\mathrm{cm}^{-1}$ is associated with the $\mathrm{SiO}_{4} \mathrm{v}_{3}\left(\mathrm{~F}_{2}\right)$ stretching vibration. The band at $806 \mathrm{~cm}^{-1}$ corresponds to the $\mathrm{SiO}_{4} v_{1}(\mathrm{~A})$ stretching vibration. The peak at $1628 \mathrm{~cm}^{-1}$ is due to the stretching and bending vibrations of water molecules adsorbed on the surface of HMS. When HMS was functionalized by amino-group, in addition to peaks associated with mesoporous silica, new peaks centred at 2934 and $2877 \mathrm{~cm}^{-1}$ were detected, corresponding to the stretching vibrations of the $\mathrm{CH}$ group, while the peaks at 1449 and $1388 \mathrm{~cm}^{-1}$ belong to the bending vibrations of those groups. Furthermore, the unique peak at $1554 \mathrm{~cm}^{-1}$ belongs to the bending vibration of $\mathrm{N}-\mathrm{H}$ groups. It should be noticed that the C-N stretching vibration in the region of 1030 $1230 \mathrm{~cm}^{-1}$ overlap with the broad peak of silanol groups and the Si-O-Si vibration. ${ }^{33}$ The results indicate that the $-\mathrm{NH}_{2}$ group has been successfully anchored onto the surface of mesoporous silica.

3.2 Properties of amino-functionalized mesoporous silica based PES-PVP composite membrane

Fig.4 shows micrographs of cross-sections of the pristine PES-PVP membrane and silica/PES-PVP composite membranes. The pristine PES-PVP membrane shows smooth cross-sectional morphology (Fig.4A), indicating dense and homogeneous micro-structure. After the addition of $2.0 \mathrm{wt} \%$ of inorganic silica fillers into PES-PVP membrane, individual spheres of HMS (Fig.4B), NH $\mathrm{N}_{2}$-meso-silica (Fig.4C) and $\mathrm{NH}_{2}$-HMS (Fig.4D) were clearly observed in the polymer matrix without aggregation. This indicates that silica spheres are homogeneously dispersed on the polymer matrix with good interfacial contact with the matrix, although the addition of inorganic fillers increases the roughness of the membrane (inset images). Nevertheless, when excess inorganic mesoporous materials are added into the polymer matrix, it would aggregate in the polymer host ${ }^{34,35}$, which would inhibit the proton 
RSC Advances. 6 (89): pp. 86575-86585, 2016.

transportation in the polymer matrix ${ }^{36}$. Occasionally, void structure of HMS was observed.

The characteristic peak of $\mathrm{C}=\mathrm{O}$ stretching vibration can be observed at $1652 \mathrm{~cm}^{-1}$ in the ATR-FTIR spectrum of PVP in the PES-PVP membrane (Fig. 5A), consistent with that reported in the literature. ${ }^{37}$ And a strong peak at $1149 \mathrm{~cm}^{-1}$ can be assigned to the symmetric stretch peak of $\mathrm{O}=\mathrm{S}=\mathrm{O}$ in PES. ${ }^{38}$ Moreover, the absorption peaks at 1461 and $1422 \mathrm{~cm}^{-1}$ are characteristic adsorptions of the pyrrolidinyl groups in PVP, as shown in Table $2^{39}$. Two characteristic intense bands associated with aromatic $\mathrm{CH}$ vibration are present at 3098 and $3068 \mathrm{~cm}^{-1}$, and aromatic skeletal and asymmetric stretching vibrations at 1577 and $1486 \mathrm{~cm}^{-1}$ are characteristic of $\mathrm{PES}^{40}$. Although silica fillers were incorporated into the PES-PVP matrix, they could not be distinguished by the ATR-FTIR spectroscopy due to the inherent existence of the amide group in PVP and the overlap for the O-Si-O bands. However, as compared with the corresponding absorption peak of the pristine PES-PVP membrane, the peak at $1652 \mathrm{~cm}^{-1}$ is red-shifted to $1648 \mathrm{~cm}^{-1}$ in the PES-PVP-H membrane. On the contrary, there is no shifting of the peak in PES-PVP-NH and PES-PVP-NS membranes. Consequently, the red-shift in the wavenumber for the $\mathrm{C}=\mathrm{O}$ absorption derives from $\mathrm{OH}$ groups and is likely due to the donation of $\mathrm{O}$ in $\mathrm{C}=\mathrm{O}$ to $\mathrm{OH}$ groups in $\mathrm{HMS}$, an indication of the formation of hydrogen bonding between $\mathrm{OH}$ and $\mathrm{C}=\mathrm{O}$ groups.

For the pristine PA/PES-PVP membrane, there is a broad peak in the range of 1050 - 900 $\mathrm{cm}^{-1}$, which is attributed to the free phosphoric acid molecules (Fig. 5B) ${ }^{41}$. Moreover, the $\mathrm{C}=\mathrm{O}$ bonds in PES-PVP red-shifted from 1652 to $1624 \mathrm{~cm}^{-1}$ after PA doping, suggesting a weak interaction with $\mathrm{OH}$ group of PA molecules via hydrogen bonding. Furthermore, the peak was shift to 1622 and $1620 \mathrm{~cm}^{-1}$ in PA/PES-PVP-NH and PA/PES-PVP-H membranes, respectively. Generally, $-\mathrm{OH}$ and $-\mathrm{NH}_{2}$ groups are protonated under acid condition to form $\mathrm{OH}_{2}{ }^{+}$and $-\mathrm{NH}_{3}{ }^{+} \cdot{ }^{42}$ And the protonated groups tend to form the hydrogen bond with $\mathrm{C}=\mathrm{O}$ in PVP, leading to the red shift of the peak of $\mathrm{C}=\mathrm{O}$. Table 2 lists the peak positions of the PES- 
RSC Advances. 6 (89): pp. 86575-86585, 2016.

PVP composite membranes with different silica fillers.

Table 2. List of peaks of PES-PVP membranes with different silica fillers.

\begin{tabular}{lll}
\hline Peaks & Wavenumber & polymer \\
\hline S=O symmetric stretch & 1149 & PES \\
$\mathrm{CSO}_{2} \mathrm{C}$ asymmetric stretch & 1319 & PES \\
C-O asymmetric stretch & 1238 & PES \\
$\mathrm{C}_{6} \mathrm{H}_{6}$ ring stretch & 1577,1486 & PES \\
$\mathrm{C}-\mathrm{H}$ stretch & 3098,3068 & PES \\
C-H phenyl & 1011 & PES \\
C-S stretch & 719 & PES \\
O-H stretch & 3405 & PVP, PES \\
C=O stretch & 1652 & PVP \\
C-H asymmetric stretch & 2954 & PVP \\
C-N vibration & 1071 & PVP \\
pyrrolidinyl & 1461,1422 & PVP \\
\hline
\end{tabular}

\section{Table 3}

Volume swelling and acid doping level of the blend composite membranes and proton conductivity of PA doped PES-PVP composite membranes under anhydrous condition at different temperatures.

\begin{tabular}{|c|c|c|c|c|c|c|c|}
\hline \multirow{2}{*}{ Samples } & \multirow{2}{*}{$\begin{array}{l}\text { Volume } \\
\text { Swelling, } \\
\%\end{array}$} & \multirow{2}{*}{$\begin{array}{l}\text { Acid doping } \\
\text {, wt } \%\end{array}$} & \multicolumn{4}{|c|}{ Proton conductivity, $\times 10^{-1} \mathrm{~S} \mathrm{~cm}^{-1}$} & \multirow{2}{*}{ Ref } \\
\hline & & & $120{ }^{\circ} \mathrm{C}$ & $140{ }^{\circ} \mathrm{C}$ & $160{ }^{\circ} \mathrm{C}$ & $180^{\circ} \mathrm{C}$ & \\
\hline PA/PES-PVP & 263 & 303 & 0.78 & 0.92 & 1.06 & 1.14 & \\
\hline PA/PES-PVP-H & 149 & 252 & 0.99 & 1.23 & 1.37 & 1.42 & This \\
\hline PA/PES-PVP-NS & 253 & 246 & 0.89 & 1.04 & 1.24 & 1.28 & work \\
\hline PA/PES-PVP-NH & 217 & 245 & 1.18 & 1.37 & 1.48 & 1.52 & \\
\hline PA/PES-PVP ${ }^{\mathrm{a}}$ & 427 & & & & & 2.1 & 14 \\
\hline $\mathrm{PA} / \mathrm{PBI}$ & 153 & 345 & 0.4 & & 0.7 & 0.7 & 43 \\
\hline
\end{tabular}

a The weight ratio of PVP is $80 \mathrm{wt} . \%$.

The thermal stability of the PES-PVP composite membranes is another critical criterion for the elevated temperature fuel cell application, as shown in Fig. 6. For the pristine PES-PVP membrane, the weight loss below $100{ }^{\circ} \mathrm{C}$ is due to the evaporation of adsorbed moisture. The 
RSC Advances. 6 (89): pp. 86575-86585, 2016.

weight loss started from around $300{ }^{\circ} \mathrm{C}$ corresponds to the degradation of PVP, while the weight loss about $500{ }^{\circ} \mathrm{C}$ results from the decomposition of $\mathrm{PES}^{14}$. Nevertheless, PES-PVPH, PES-PVP-NH and PES-PVP-NS membranes show higher degradation temperature for PVP than the pristine PES-PVP membrane. The result indicates that the addition of mesoporous silica materials enhance the thermal stability of PES-PVP composite membranes.

Table 3 summarizes the PA uptake and volume swelling ratios of PES-PVP composite membranes. The PA uptake of pristine PES-PVP composite membrane was 303 wt.\%, and the volume swelling ratio was $263 \%$. When inorganic materials were added into the composite membranes, the PA uptake slightly decreased to 252 wt.\%, 245 wt.\% and 246 wt.\% for PA/PES-PVP-H, PA/PES-PVP-NH, and PA/PES-PVP-NS composite membranes, respectively. This may be due to the decreased acid adsorption sites after the addition of silica materials in polymer matrix. ${ }^{44}$ Moreover, PA/PES-PVP-NH and PA/PES-PVP-NS shows higher volume swelling ratio than that of PA/PES-PVP-H, but lower than that of the pristine PES-PVP composite membrane, indicating the hindrance effect of silica fillers for the volume swelling of the PES-PVP membrane. The lower volume swelling of PES-PVP composite membranes after the addition of silica fillers is likely due to the weak interaction of silica and PVP molecules, as indicated by ATR-FTIR characterization.

\subsection{Proton conductivity and cell performance PES-PVP composite membranes}

Fig. 7A shows the proton conductivity of the PA doped PES-PVP composite membranes. The proton conductivity of PA/PES-PVP membrane is $7.8 \times 10^{-2} \mathrm{~S} \mathrm{~cm}^{-1}$ at $120{ }^{\circ} \mathrm{C}$, anhydrous condition. And it increased to $1.14 \times 10^{-1} \mathrm{~S} \mathrm{~cm}^{-1}$ when the temperature was improved to 180 ${ }^{\circ} \mathrm{C}$. The conductivity value is within the reported proton conductivity of PA/PES-PVP composite membranes with 60 wt.\% and 80 wt.\% $\mathrm{PVP}^{14}$. The addition of inorganic silica fillers to the PA/PES-PVP membrane enhances the proton conductivity of the membrane. The 
RSC Advances. 6 (89): pp. 86575-86585, 2016.

proton conductivity of the PA/PES-PVP-H composite membrane is $1.42 \times 10^{-1} \mathrm{~S} \mathrm{~cm}^{-1}$ at 180 ${ }^{\circ} \mathrm{C}$. And the proton conductivity is further increased to $1.52 \times 10^{-1} \mathrm{~S} \mathrm{~cm}^{-1}$ for the PA/PESPVP-NH membrane. The proton conductivity of the PA/PES-PVP-NH membrane is significantly higher than $\sim 2.0 \times 10^{-2} \mathrm{~S} \mathrm{~cm}^{-1}$ of the state-of-the-art PA/PBI membranes measured under the similar condition. ${ }^{45}$ The excellent conductivity of the PA/PES-PVP-NH membrane can be contributed to the fact that $-\mathrm{NH}_{2}$ groups in the highly ordered channels of mesoporous silica are favourable to form effective proton conducting paths to improve the proton conductivity ${ }^{24}$. The PA/PES-PVP-NH membrane also shows superior proton conductivity as compared to the PA/PES-PVP-NS membrane, although $\mathrm{NH}_{2}-\mathrm{HMS}$ and $\mathrm{NH}_{2}$ meso-silica have the comparable - $\mathrm{NH}_{2}$ content and both membranes have similar PA uptake.

The activation energy for the proton transportation in different PA-doped PES-PVP composite membranes was calculated via the Arrhenius equations, as shown in Fig. 7B. The activation energy for the pristine PA/PES-PVP membrane is $13.1 \mathrm{~kJ} \mathrm{~mol}^{-1}$. After the addition of the silica fillers, the composite membranes show lower activation energy in comparison with the pristine PA/PES-PVP membrane. For instance, the proton diffusion activation energy for the membrane of PA/PES-PVP-NH is $9.8 \mathrm{~kJ} \mathrm{~mol}^{-1}$, which is lower than that of the PA/PES-PVP-H. The low activation energy of PA/PES-PVP-NH membrane in comparison with PA/PES-PVP-H may be due to the facilitated proton diffusion in silica fillers by the hydrogen bond between the $-\mathrm{NH}_{2}$ groups and $\mathrm{PA}$ molecules. Moreover, for the pristine PA/PES-PVP membrane, protons in PA molecules tend to interact with oxygen in the $\mathrm{C}=\mathrm{O}$ group of PVP molecules via hydrogen bond, and migrates via a hopping mechanism through neighbouring units. ${ }^{46}$ On the other hand, protons in free acid at a high PA doping level hop along the mixed anion chains of $\mathrm{H}_{2} \mathrm{PO}_{4}{ }^{-} / \mathrm{HPO}_{4}{ }^{2-}$ under anhydrous condition. ${ }^{47}$ The high activation energy of PA/PES-PVP membrane indicates that the proton transportation in the membranes is primarily via Grotthuss mechanism. ${ }^{48}$ However, it has been revealed that when 
RSC Advances. 6 (89): pp. 86575-86585, 2016.

the activation energy of PA/PBI is in the range of $8-10 \mathrm{~kJ} \mathrm{~mol}^{-1}$ that is close to that of $\mathrm{H}_{3} \mathrm{PO}_{4}$ solution with a concentration range of 85 - 93 wt.\%, PA would perform in the state of quasi-liquid like conductor due to the presence of water molecules. ${ }^{49}$ Thus, the low proton diffusion activation energy of PA/PES-PVP-NH $\left(9.8 \mathrm{~kJ} \mathrm{~mol}^{-1}\right)$ indicates the existence of quasi-liquid like conductor in the membrane. That may be due to the high water retention capacity of $\mathrm{NH}_{2}$-HMS for PES-PVP membrane at elevated temperatures under anhydrous conditions. Although PA/PES-PVP-NH and PA/PES-PVP-NS shows similar PA uptake and amino group content for $\mathrm{NH}_{2}$-HMS and $\mathrm{NH}_{2}$-meso-silica, the hollow silica structure shows positive effects on the water retention. This probably explains the observation of higher proton conductivity and lower activation energy of PA/PES-PVP-NH membranes as compared with PA/PES-PVP-NS membranes.

Fig. 8 shows the polarization performance of PA-doped silica/PES-PVP composite membranes based fuel cells. The open circuit voltage for all cells was $\sim 0.9 \mathrm{~V}$, indicating the low $\mathrm{H}_{2}$ crossover, most likely due to the dense structure of the inorganic-organic hybrid composite membranes. The peak power density of the PA/PES-PVP membrane fuel cell is $105 \mathrm{~mW} \mathrm{~cm}{ }^{-2}$ at $120{ }^{\circ} \mathrm{C}$ without external humidification (Fig.8A). And it increased to 249 $\mathrm{mW} \mathrm{cm}^{-2}$ when the temperature increased to $180{ }^{\circ} \mathrm{C}$. Cells based on PES-PVP composite membranes with inorganic fillers demonstrate higher power output than the pristine PA/PESPVP membrane fuel cell because of the high proton conductivity. For instance, the peak power density of PA/PES-PVP-H membrane fuel cell was $337 \mathrm{~mW} \mathrm{~cm}{ }^{-2}$ at $180{ }^{\circ} \mathrm{C}$, and it significantly increased to $480 \mathrm{~mW} \mathrm{~cm}^{-2}$ for PA/PES-PVP-NH membrane cell, which is 92.7 \% higher than that of the pristine PA/PES-PVP membrane cell measured under the identical condition. The peak power density of the fuel cells at different temperatures are summarized in Fig.8B, and the performance follows the order of PA/PES-PVP-NH > PA/PES-PVP-H> PA/PES-PVP-NS > PA/PES-PVP. 
RSC Advances. 6 (89): pp. 86575-86585, 2016.

Based on the proton conductivity and activation energy results, the proton conduction mechanism and role of amino-functionalized mesoporous silica in PES-PVP composite membranes are schematically shown in Fig.9, taking $\mathrm{NH}_{2}$-HMS as example. In the PES-PVP composite membrane, PES primarily functions as the support for the mechanical strength and stability of the composite membrane, while PVP plays the role as the proton transportation network in nanoscale domains. In addition, functionalized amino group favours to form the hydrogen-bond network with PA in the mesoporous channels and the void in $\mathrm{NH}_{2}-\mathrm{HMS}$ would serve as an acidic reservoir ${ }^{16}$. In addition to the normal proton diffusion path along the functional unit in PVP and mixed anion chains of $\mathrm{H}_{2} \mathrm{PO}_{4}{ }^{-} / \mathrm{HPO}_{4}{ }^{2-}$ in the polymeric matrix, protons are also transferred along the hydrogen bond network. Moreover, the presence of water in the $\mathrm{NH}_{2}$-HMS structure provides the quasi-liquid like conduction of protons. That is, the superior water retention capability at elevated temperatures and anhydrous conditions of $\mathrm{NH}_{2}$-HMS promotes the proton transportation and cell performance for the PES-PVP composite membrane.

Durability of a membrane based fuel cell is another critical criterion for the feasibility of the membrane in the fuel cell application at elevated temperatures. Fig.10A shows the durability performance of the PA/PES-PVP-NH composite membrane fuel cell at $160{ }^{\circ} \mathrm{C}$ with a current load of $200 \mathrm{~mA} \mathrm{~cm}{ }^{-2}$. The pristine PA/PES-PVP membrane was employed as the control group. As shown in Fig.10A, there is a slight decrease on the voltage of PA/PES-PVP membrane fuel cell, and then it is stable up to 120 h. For the PA/PES-PVP-NH membrane fuel cell, the initial cell voltage was $0.53 \mathrm{~V}$ and slightly decreased to $0.50 \mathrm{~V}$ after tested for 96 $\mathrm{h}$ with a degradation rate of $0.3 \mathrm{mV} \mathrm{h}^{-1}$. The degradation rate is over one order of magnitude higher than that of the PA/PBI composite membrane at the identical condition ${ }^{50}$. Nevertheless, the degradation rate increased to $1.4 \mathrm{mV} \mathrm{h}^{-1}$ with further polarization test. The results indicate that PA/PES-PVP-NH shows a lower stability than PA/PES-PVP in fuel cell 
RSC Advances. 6 (89): pp. 86575-86585, 2016.

operations.

In order to reveal the reasons for the degradation of PA/PES-PVP-NH membrane fuel cells, electrochemical impedance technique was employed (see Fig.10B). The result indicates that the membrane resistance is stable, while the electrode resistance is slightly decreased during the fuel cell operation. In other words, the fuel cell performance degradation is not due to the PA leaching or degradation of the Pt electrocatalysts. ${ }^{51,52}$ On the other hand, the open cell voltage of the PA/PES-PVP-NH composite membrane fuel cell dropped from $0.92 \mathrm{~V}$ initially to $0.72 \mathrm{~V}$ at $96 \mathrm{~h}$ and $0.58 \mathrm{~V}$ at $120 \mathrm{~h}$, while the polarization curves were almost the same at high current density during the fuel cell operation (Fig.10C). The decrease in the open cell voltage suggests the increase of fuel permeation from the anode to the cathode during the fuel cell operation, which is most likely contributed to the decrease of the mechanical strength of the composite membrane, such as phase separation etc. This hypothesis appears to be confirmed by the broken of the composite membrane after the fuel cell polarization test.

\section{Conclusions}

Three types of mesoporous silica materials were successfully synthesized and incorporated into the PES-PVP matrix, forming inorganic-organic hybrid composite membranes. In comparison with the pristine PA-doped PES-PVP membrane, the inorganic-organic hybrid composite membranes showed lower PA uptake and higher proton conductivity, achieving $1.52 \times 10^{-1} \mathrm{~S} \mathrm{~cm}^{-1}$ at $180{ }^{\circ} \mathrm{C}$ with the addition of $\mathrm{NH}_{2}$-HMS. The high proton conductivity is most likely due to the facilitated proton transportation in the ordered mesoporous channels via the hydrogen bonds between the $-\mathrm{NH}_{2}$ groups and $\mathrm{H}_{3} \mathrm{PO}_{4}$ and the high water retention of hollow structure in the silica fillers. Cell performance also confirms the superiority of the addition of inorganic fillers in the PES-PVP membrane, and the highest peak power density of $480 \mathrm{~mW} \mathrm{~cm}^{-2}$ was obtained on the PA/PES-PVP-NH membrane at $180{ }^{\circ} \mathrm{C}$ without external 
RSC Advances. 6 (89): pp. 86575-86585, 2016.

humidification, which is $92.7 \%$ higher than that of PA/PES-PVP tested at the same condition. The decrease in the open cell voltage of PA/PES-PVP-NH membrane fuel cells suggests the increase of fuel crossover during the fuel cell operation, most likely due to the decrease of the mechanical strength of the composite inorganic-organic hybrid membranes. Thus further enhancement of the mechanical strength of the composite membrane will significantly increase the durability of the cells. Overall, the inorganic-organic composite membranes based on amino-functionalized hollow mesoporous silica materials show promising potential in the application of elevated temperature proton exchange membrane fuel cells.

\section{Acknowledgements}

This work is financially supported by Australia Research Council under the Discovery Project Scheme (project number: DP150102025 and DP150102044). The authors acknowledge the facilities, and the scientific and technical assistance of the National Imaging Facility at the Centre for Microscopy, Characterization\& Analysis, the University of Western Australia, a facility funded by the University, State, and Commonwealth Government as well as the facilities, scientific and technical assistance of the Curtin University Microscopy \& Microanalysis Facility, which is partially funded by the University, State and Commonwealth Governments. The synchrotron SAXS was carried out on the SAXS beamline at the Australian Synchrotron, Victoria, Australia.

\section{References:}

1. K. Jiao and X. Li, Prog. Energy Combust. Sci., 2011, 37, 221-291.

2. B. P. Tripathi and V. K. Shahi, Prog. Polym. Sci., 2011, 36, 945-979.

3. Q. Li, R. H. He, J. O. Jensen and N. J. Bjerrum, Chem. Mater., 2003, 15, 4896-4915.

4. J. Zeng, B. He, K. Lamb, R. De Marco, P. K. Shen and S. P. Jiang, Chem. Commun., 2013, 49, 4655-4657.

5. Y.-S. Ye, G.-W. Liang, B.-H. Chen, W.-C. Shen, C.-Y. Tseng, M.-Y. Cheng, J. Rick, Y.-J. Huang, F.-C. Chang and B.-J. Hwang, J. Power Sources, 2011, 196, 5408-5415.

6. R. Marschall, M. Sharifi and M. Wark, Microporous Mesoporous Mater., 2009, 123, 21-29. 
RSC Advances. 6 (89): pp. 86575-86585, 2016.

7. S. J. Park, D. H. Lee and Y. S. Kang, J. Membr. Sci., 2010, 357, 1-5.

8. E. Quartarone and P. Mustarelli, Energy Environ. Sci., 2012, 5, 6436-6444.

9. Q. Li, J. O. Jensen, R. F. Savinell and N. J. Bjerrum, Prog. Polym. Sci., 2009, 34, 449-477.

10. T. Steenberg, H. A. Hjuler, C. Terkelsen, M. T. R. Sanchez, L. N. Cleemann and F. C. Krebs, Energy Environ. Sci., 2012, 5, 6076-6080.

11. J. K. Kallitsis, M. Geormezi and S. G. Neophytides, Polym. Inter., 2009, 58, 1226-1233.

12. D. Aili, L. N. Cleemann, Q. Li, J. O. Jensen, E. Christensen and N. J. Bjerrum, J. Mater. Chem., 2012, 22, 5444-5453.

13. Z. Guo, X. Xu, Y. Xiang, S. Lu and S. P. Jiang, J. Mater. Chem. A, 2015, 3, 148-155.

14. X. Xu, H. Wang, S. Lu, Z. Guo, S. Rao, R. Xiu and Y. Xiang, J. Power Sources, 2015, 286, 458-463.

15. Z. Guo, R. Xiu, S. Lu, X. Xu, S. Yang and Y. Xiang, J. Mater. Chem. A, 2015, 3, 8847-8854.

16. Y. Zhao, H. Yang, H. Wu and Z. Jiang, J. Membr. Sci., 2014, 469, 418-427.

17. Suryani, Y.-N. Chang, J.-Y. Lai and Y.-L. Liu, J. Membr. Sci., 2012, 403-404, 1-7.

18. A. K. Mishra, N. H. Kim and J. H. Lee, J. Membr. Sci., 2014, 449, 136-145.

19. L. Zhang, H. Q. He, R. K. S/O Abdul Rasheed, W. J. Zhou, Y. H. Xue, O. L. Ding and S. H. Chan, J. Power Sources, 2013, 221, 318-327.

20. Y. Zhao, H. Yang, H. Wu and Z. Jiang, J. Power Sources, 2014, 270, 292-303.

21. Y. Yin, W. Deng, H. Wang, A. Li, C. Wang, Z. Jiang and H. Wu, J. Mater. Chem. A, 2015, 3, 16079-16088.

22. Q. Li, H. Zhang, Z. Tu, J. Yu, C. Xiong and M. Pan, J. Membr. Sci., 2012, 423, 284-292.

23. S. Ghosh, S. Maity and T. Jana, J. Mater. Chem., 2011, 21, 14897-14906.

24. S. Singha and T. Jana, ACS Appl. Mater. Interfaces, 2014, 6, 21286-21296.

25. S. Zhu, L. Yan, D. Zhang and Q. Feng, Polymer, 2011, 52, 881-892.

26. X. Fang, Z. Liu, M.-F. Hsieh, M. Chen, P. Liu, C. Chen and N. Zheng, ACS Nano, 2012, 6, 4434-4444.

27. A. Danon, P. C. Stair and E. Weitz, J. Phys. Chem. C, 2011, 115, 11540-11549.

28. X. She, L. Chen, C. Li, C. He, L. He and L. Kong, J. Nanomater., 2015, 2015, 9.

29. N. Venkatathri, Materials Science and Engineering: C, 2008, 28, 1260-1264.

30. X. Ma, Y. Zhao, K. W. Ng and Y. Zhao, Chem. Eur. J, 2013, 19, 15593-15603.

31. J. L. Blin, C. Gérardin, L. Rodehüser, C. Selve and M. J. Stébé, Chem. Mater., 2004, 16, 5071-5080.

32. J. Gao, X. Zhang, Y. Lu, S. Liu and J. Liu, Chemistry - A European Journal, 2015, 21, 7403-7407.

33. N. Shadjou and M. Hasanzadeh, RSC Adv., 2014, 4, 18117-18126.

34. M. X. Reinholdt and S. Kaliaguine, Langmuir, 2010, 26, 11184-11195.

35. M. J. Kayser, M. X. Reinholdt and S. Kaliaguine, J. Phys. Chem. B, 2010, 114, 8387-8395.

36. Y.-F. Lin, C.-Y. Yen, C.-C. M. Ma, S.-H. Liao, C.-H. Lee, Y.-H. Hsiao and H.-P. Lin, J. Power Sources, 2007, 171, 388-395.

37. K. M. Koczkur, S. Mourdikoudis, L. Polavarapu and S. E. Skrabalak, Dalton Trans., 2015, 44, 1788317905.

38. I. Ahmed, A. Idris, M. Y. Noordin and R. Rajput, Ind. Eng. Chem. Res., 2011, 50, 2272-2283.

39. H. Liu, B. Zhang, H. Shi, Y. Tang, K. Jiao and X. Fu, J. Mater. Chem., 2008, 18, 2573-2580.

40. S. Belfer, R. Fainchtain, Y. Purinson and O. Kedem, J. Membr. Sci., 2000, 172, 113-124.

41. J. A. Asensio, S. Borrós and P. Gómez-Romero, J. Polym. Sci., Part A: Polym. Chem., 2002, 40, 37033710.

42. H. Tang, M. Pan and S. P. Jiang, Dalton Trans., 2011, 40, 5220-5227.

43. D. Aili, T. Allward, S. M. Alfaro, C. Hartmann-Thompson, T. Steenberg, H. A. Hjuler, Q. Li, J. O. Jensen and E. J. Stark, Electrochimica Acta, 2014, 140, 182-190.

44. D. Aili, J. Zhang, M. T. Dalsgaard Jakobsen, H. Zhu, T. Yang, J. Liu, M. Forsyth, C. Pan, J. O. Jensen, L. N. Cleemann, S. P. Jiang and Q. Li, J. Mater. Chem. A, 2016, 4, 4019-4024.

45. C. Xu, X. Liu, J. Cheng and K. Scott, J. Power Sources, 2015, 274, 922-927.

46. J. C. Lassegues, in Proton conductors: Solids, Membranes and Gels-Materials and Devices, Cambridge University Press, 2008, p. 318.

47. M. F. H. S. and and W. H. Meyer, Anu. Rev. Mater. Res., 2003, 33, 233-261.

48. Y. Liu, J. Wang, H. Zhang, C. Ma, J. Liu, S. Cao and X. Zhang, J. Power Sources, 2014, 269, 898-911.

49. R. H. He, Q. Li, G. Xiao and N. J. Bjerrum, J. Membr. Sci., 2003, 226, 169-184.

50. T. J. Schmidt and J. Baurmeister, J. Power Sources, 2008, 176, 428-434.

51. Y. Zhai, H. Zhang, D. Xing and Z.-G. Shao, J. Power Sources, 2007, 164, 126-133.

52. Y. Zhai, H. Zhang, G. Liu, J. Hu and B. Yia, J. Electrochem. Soc., 2007, 154, B72-B76. 
RSC Advances. 6 (89): pp. 86575-86585, 2016.

\section{Figure captions}

Fig.1 TEM images of (A, B) HMS, (C, D) $\mathrm{NH}_{2}$-HMS and (E, F) $\mathrm{NH}_{2}$-meso-silica.

Fig.2 (A) $\mathrm{N}_{2}$ adsorption isotherms, (B) pore size distributions, (C) SAXS profiles of and (D) TGA curves of HMS, $\mathrm{NH}_{2}-\mathrm{HMS}$ and $\mathrm{NH}_{2}$-meso-silica.

Fig.3 (A) ${ }^{13} \mathrm{C}$ CP/MAS and (B) ${ }^{29} \mathrm{Si}$ MAS NMR of $\mathrm{NH}_{2}$-HMS. (C) ATR-FTIR spectra of HMS and $\mathrm{NH}_{2}$-HMS.

Fig. 4 SEM images of the PES-PVP composite membranes with (A) pristine PES-PVP, (B) HMS (PES-PVP-H), (C) NH2-meso-silica(PES-PVP-NS) and (D) $\mathrm{NH}_{2}$-HMS (PES-PVP-NH). The content of mesoporous materials is $2.0 \mathrm{wt} \%$.

Fig.5 ATR-FTIR profiles of (A) PES-PVP composite membranes and (B) PA-doped PESPVP composite membranes with different silica materials.

Fig.6 TGA profiles of the PES-PVP composite membrane with different types of mesoporous silica materials. Inset is the image of derivation weight as a function of temperatures.

Fig.7 (A) The proton conductivity and (B) the activation energy for proton transportation of PA doped PES-PVP composite membranes under anhydrous conditions.

Fig.8 (A) and (B) are cell performance at $180{ }^{\circ} \mathrm{C}$ and peak power density conclusions of the PES-PVP composite membrane fuel cells, respectively. No external humidifier was used. The Pt loading for both the anode and the cathode is $0.35 \mathrm{mg} \mathrm{cm}^{-2}$.

Fig.9 Scheme of the formation of mesoporous silica based PES-PVP composite membranes and the function of silica fillers in the polymer matrix (Take $\mathrm{NH}_{2}-\mathrm{HMS}$ as example.).

Fig.10 (A) The durability fuel cell performance of with a current load of $200 \mathrm{~mA} \mathrm{~cm}^{-2}$ at 160 ${ }^{\circ} \mathrm{C}$ in $\mathrm{H}_{2} / \mathrm{O}_{2}$ without external humidification. The Pt loading for both the anode and the 
RSC Advances. 6 (89): pp. 86575-86585, 2016.

cathode is $0.26 \mathrm{mg} \mathrm{cm}^{-2}$ for the PA/PES-PVP-NH fuel cell, while it is $0.35 \mathrm{mg} \mathrm{cm}^{-2}$ for the PA/PES-PVP fuel cell. (B) and (C) are the impedance at $0.5 \mathrm{~V}$ and cell performance of the PA/PES-PVP-NH fuel cell at different time.

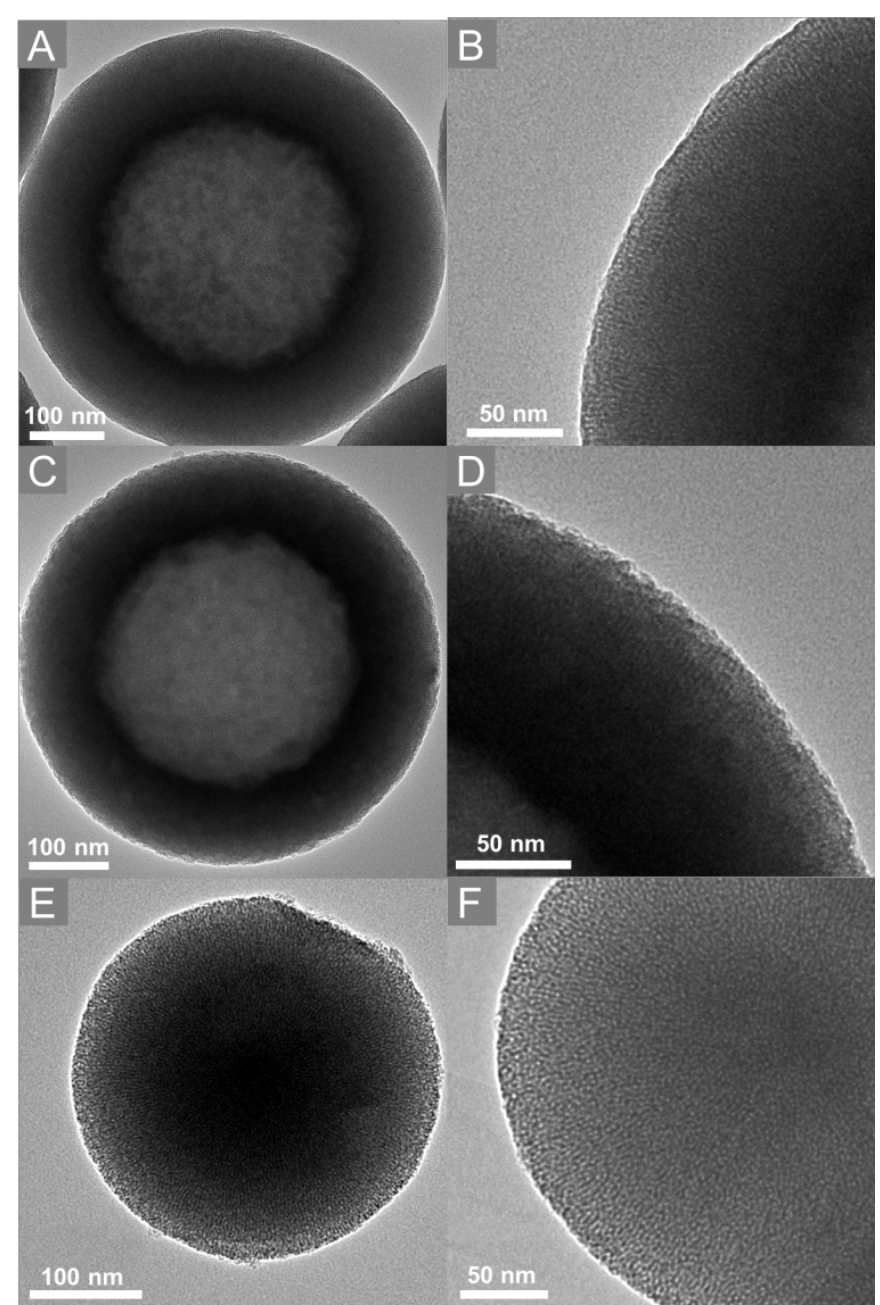

Fig.1 TEM images of (A, B) HMS, (C, D) $\mathrm{NH}_{2}$-HMS and (E, F) $\mathrm{NH}_{2}$-meso-silica. 
RSC Advances. 6 (89): pp. 86575-86585, 2016.
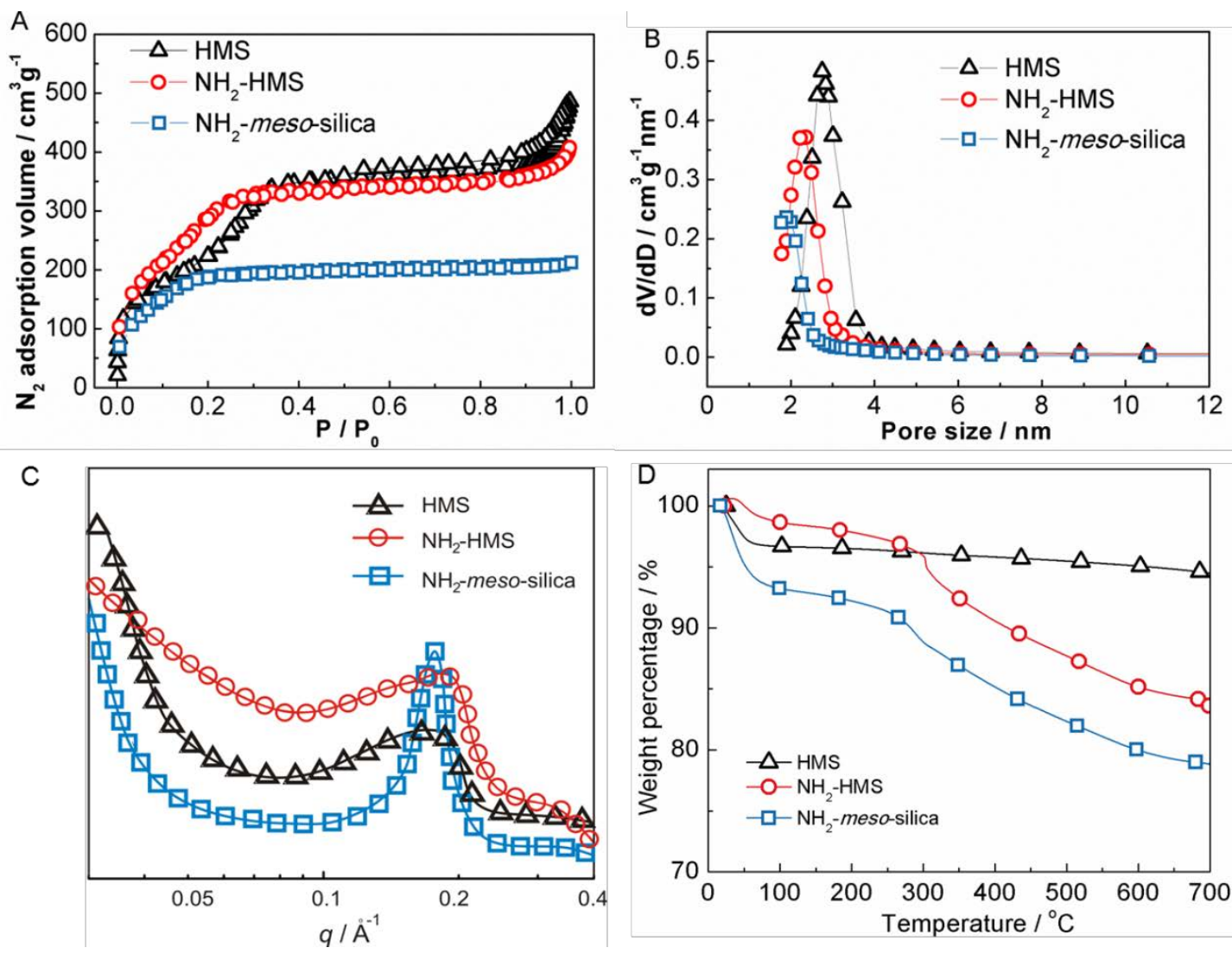

Fig.2 (A) $\mathrm{N}_{2}$ adsorption isotherms, (B) pore size distributions, (C) SAXS profiles of and (D) TGA curves of HMS, $\mathrm{NH}_{2}-\mathrm{HMS}$ and $\mathrm{NH}_{2}$-meso-silica. 
RSC Advances. 6 (89): pp. 86575-86585, 2016.

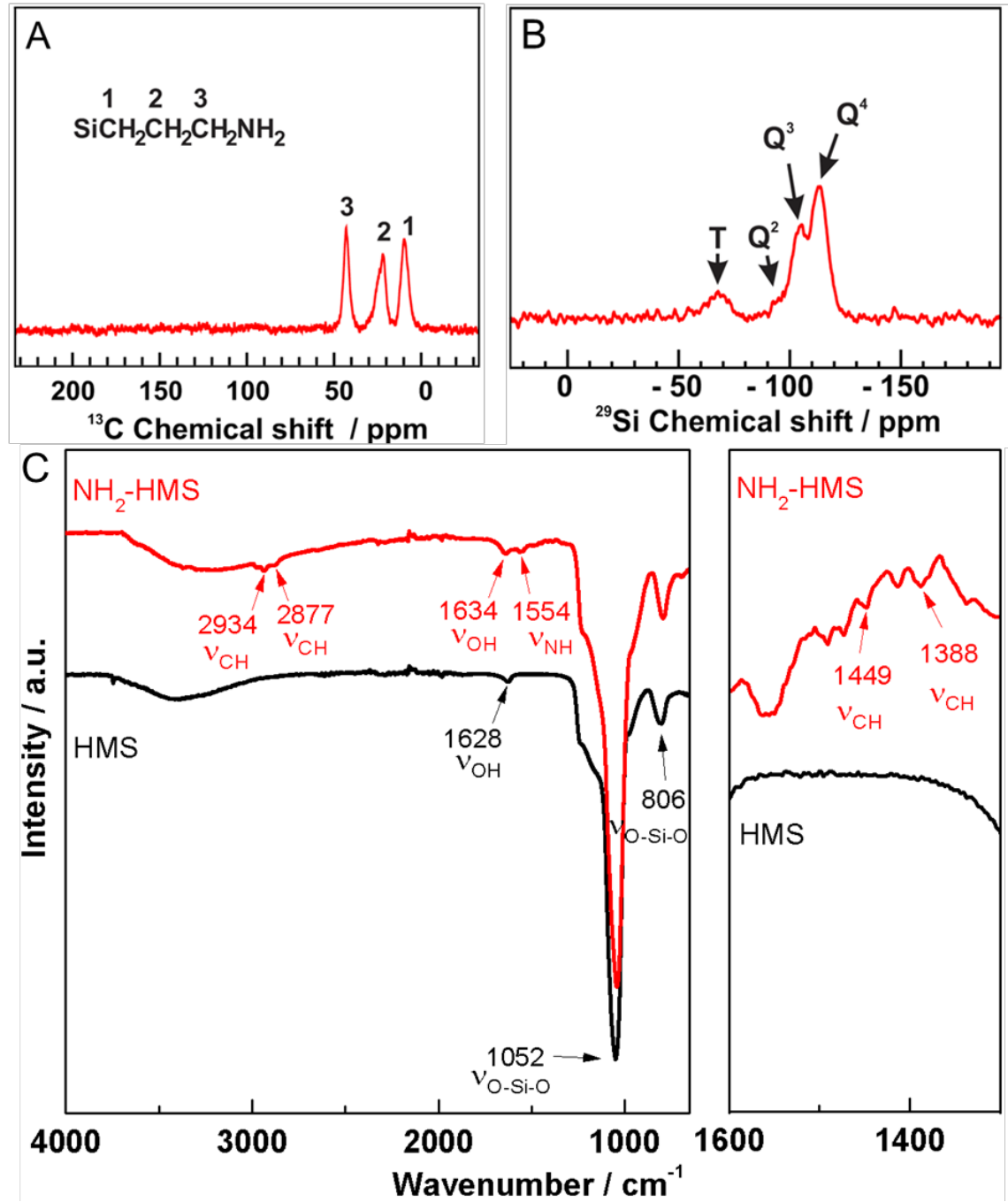

Fig.3 (A) ${ }^{13} \mathrm{C}$ CP/MAS and (B) ${ }^{29} \mathrm{Si}$ MAS NMR of $\mathrm{NH}_{2}$-HMS. (C) ATR-FTIR spectra of HMS and $\mathrm{NH}_{2}$-HMS. 
RSC Advances. 6 (89): pp. 86575-86585, 2016.

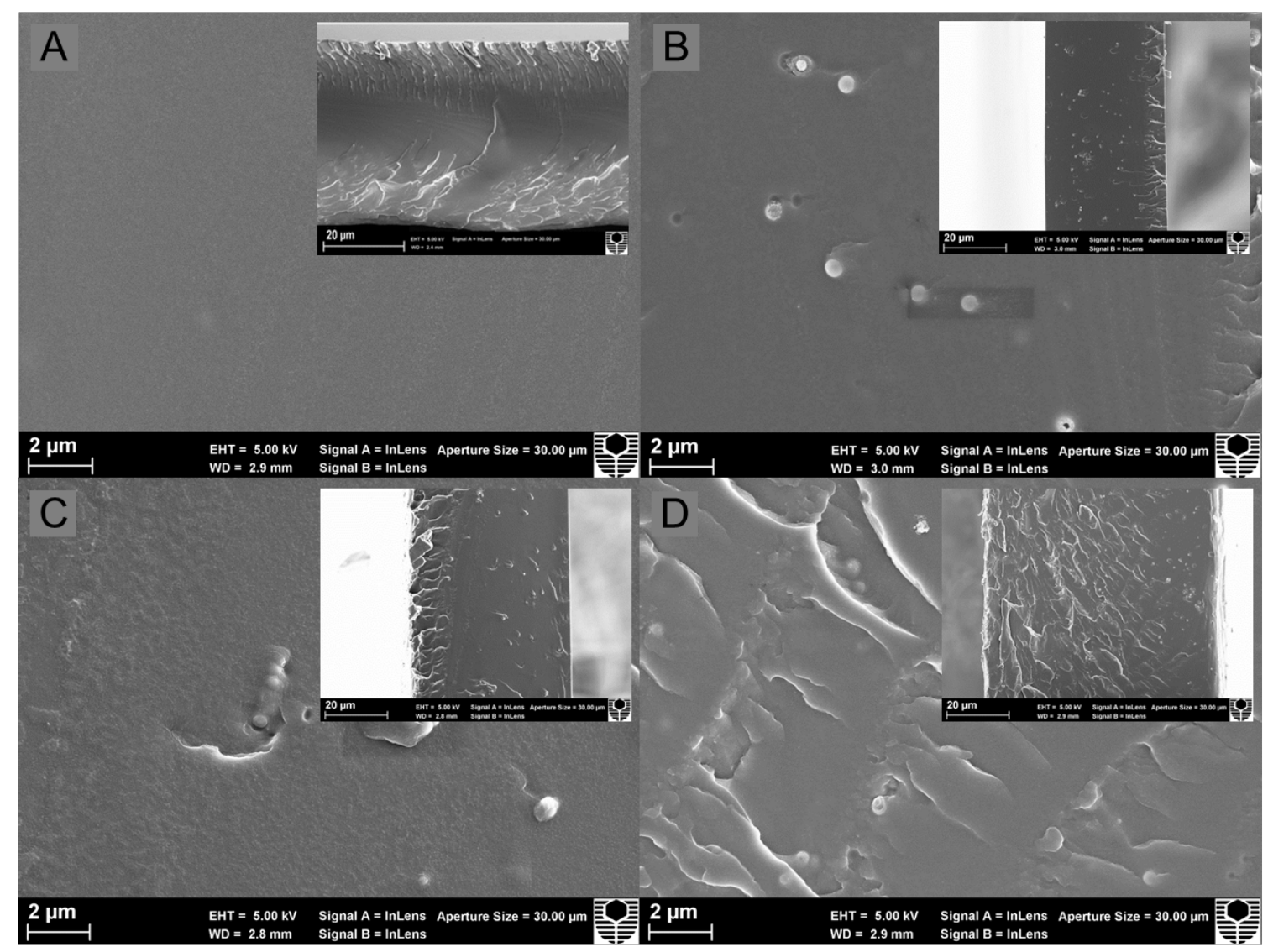

Fig. 4 SEM images of the PES-PVP composite membranes with (A) pristine PES-PVP, (B) HMS (PES-PVP-H), (C) NH -meso-silica(PES-PVP-NS) and (D) $\mathrm{NH}_{2}-\mathrm{HMS}$ (PES-PVP-NH). The content of mesoporous materials is $2.0 \mathrm{wt} \%$. 

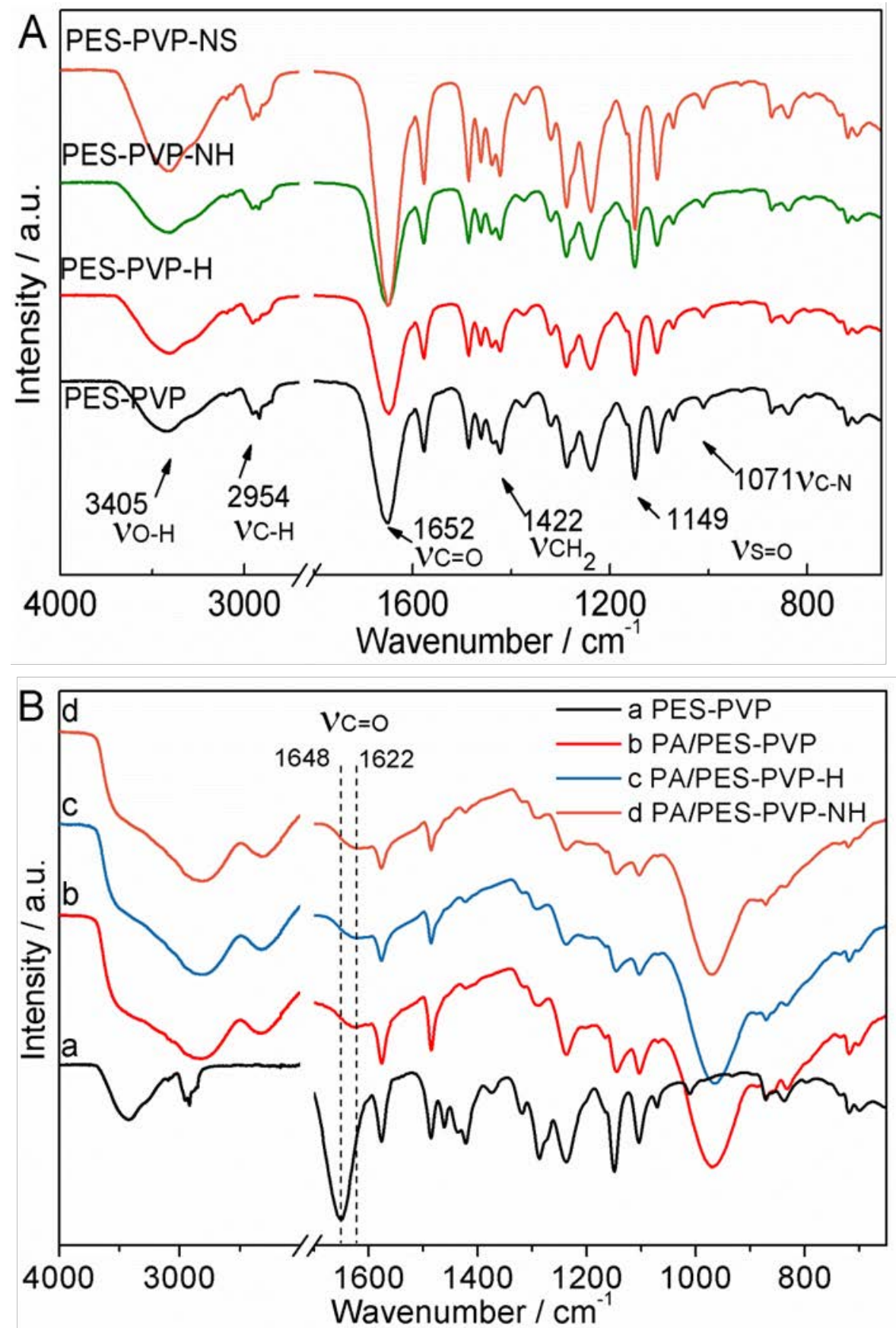

Fig.5 ATR-FTIR profiles of (A) PES-PVP composite membranes and (B) PA-doped PESPVP composite membranes with different silica materials. 
RSC Advances. 6 (89): pp. 86575-86585, 2016.

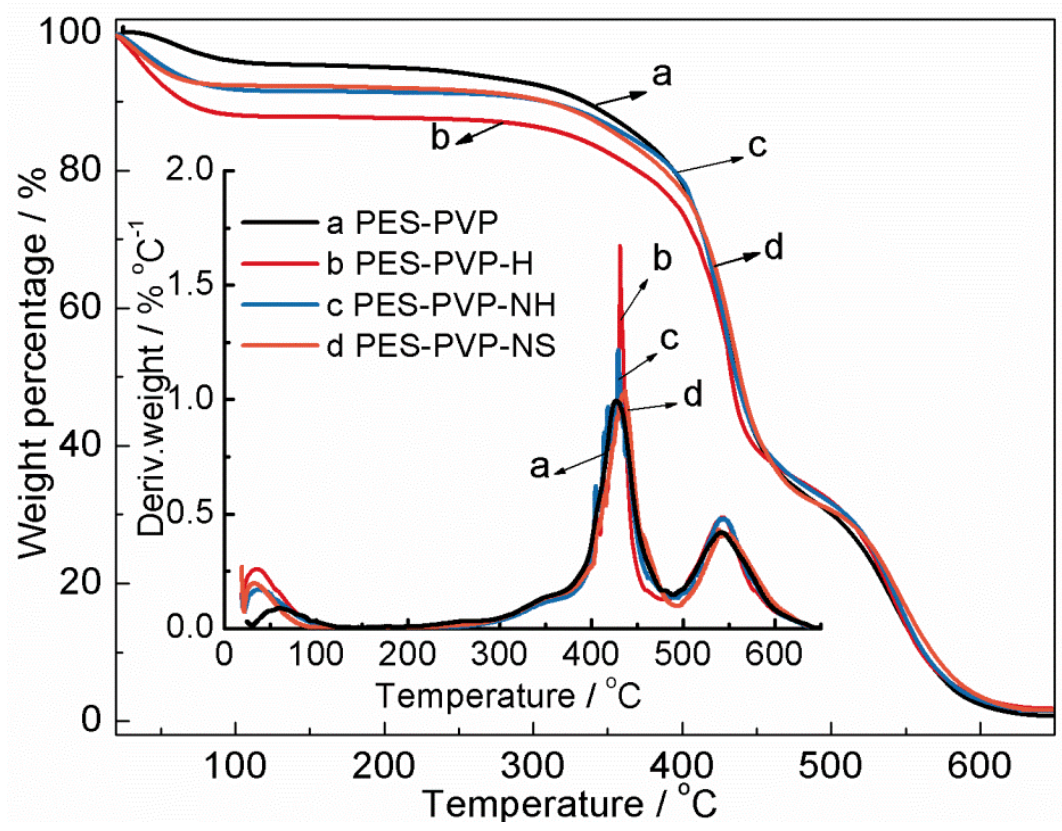

Fig.6 TGA profiles of the PES-PVP composite membrane with different types of mesoporous silica materials. Inset is the image of derivation weight as a function of temperatures. 
RSC Advances. 6 (89): pp. 86575-86585, 2016.

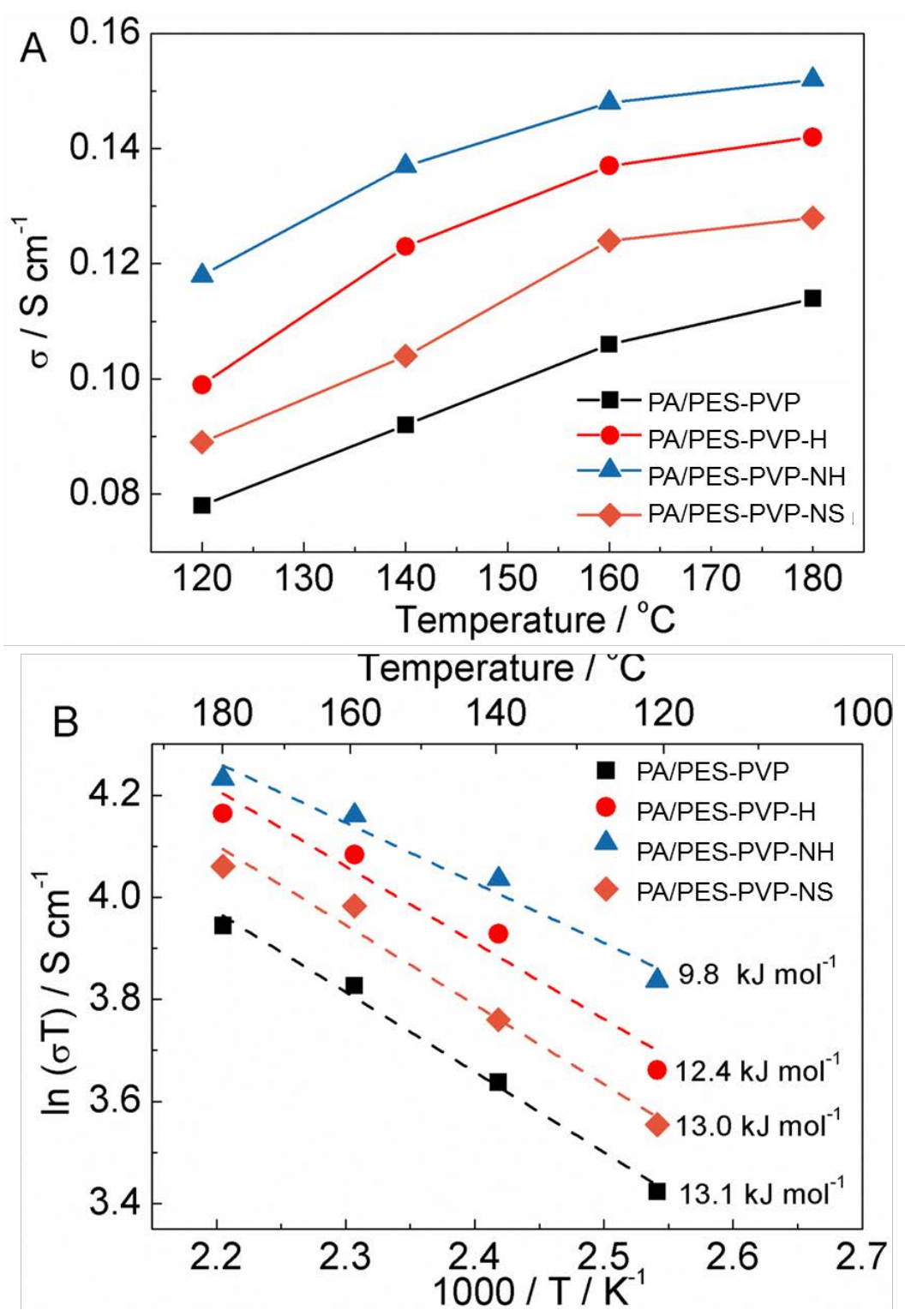

Fig.7 (A) The proton conductivity and (B) the activation energy for proton transportation of PA doped PES-PVP composite membranes under anhydrous conditions. 
RSC Advances. 6 (89): pp. 86575-86585, 2016.
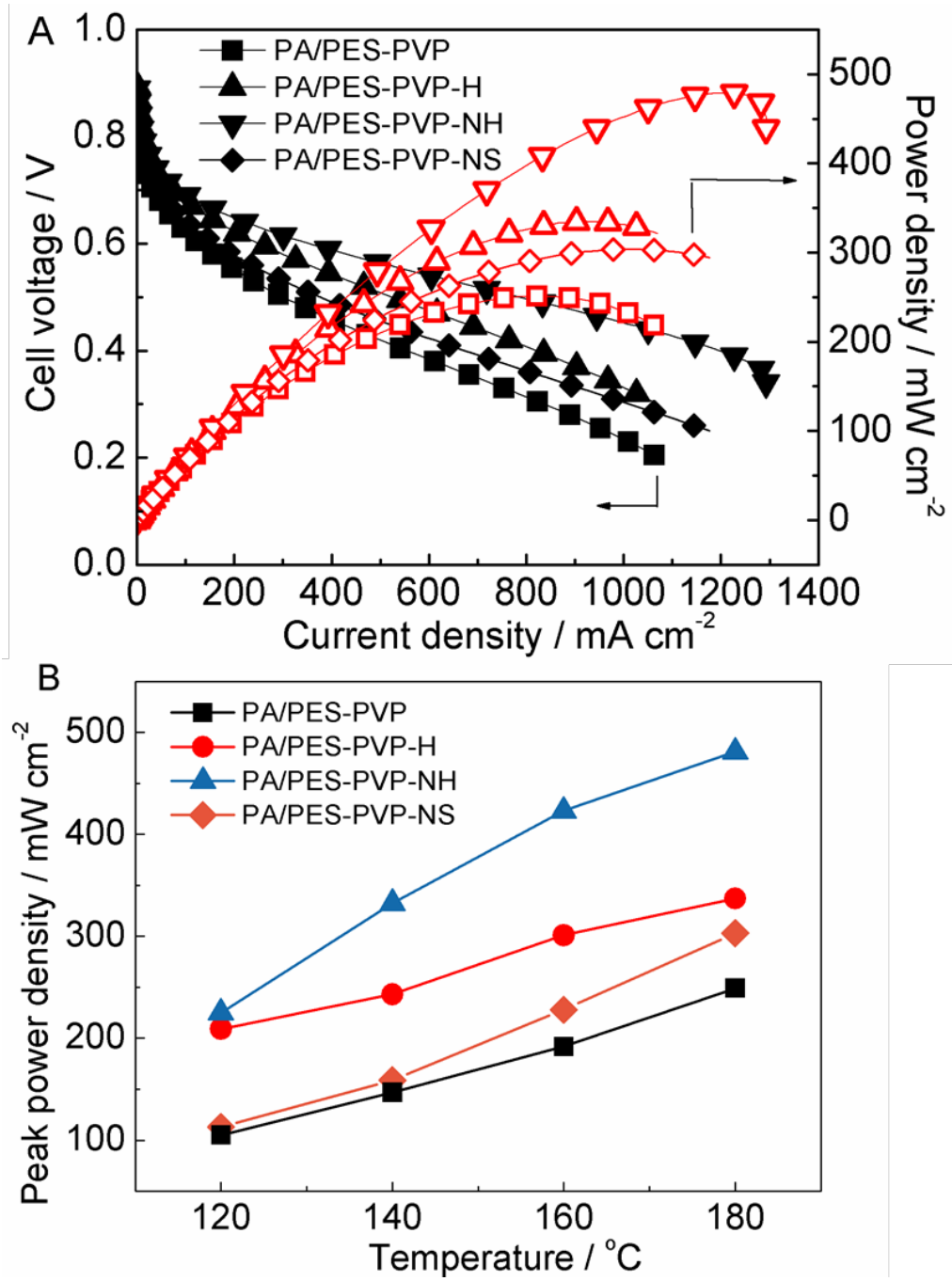

Fig.8 (A) and (B) are cell performance at $180{ }^{\circ} \mathrm{C}$ and peak power density conclusions of the PES-PVP composite membrane fuel cells, respectively. No external humidifier was used. The Pt loading for both the anode and the cathode is $0.35 \mathrm{mg} \mathrm{cm}^{-2}$. 
RSC Advances. 6 (89): pp. 86575-86585, 2016.

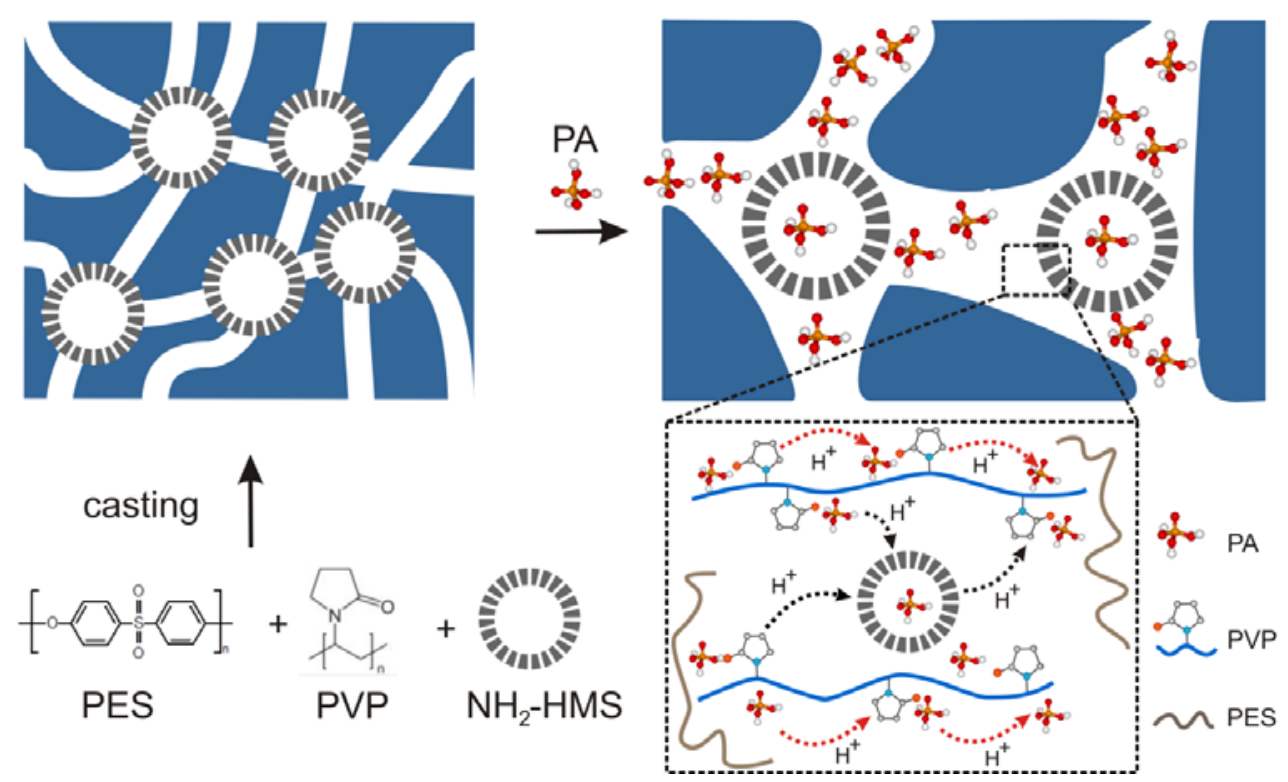

Fig.9 Scheme of the formation of mesoporous silica based PES-PVP composite membranes and the function of silica fillers in the polymer matrix (Take $\mathrm{NH}_{2}$-HMS as example). 
RSC Advances. 6 (89): pp. 86575-86585, 2016.
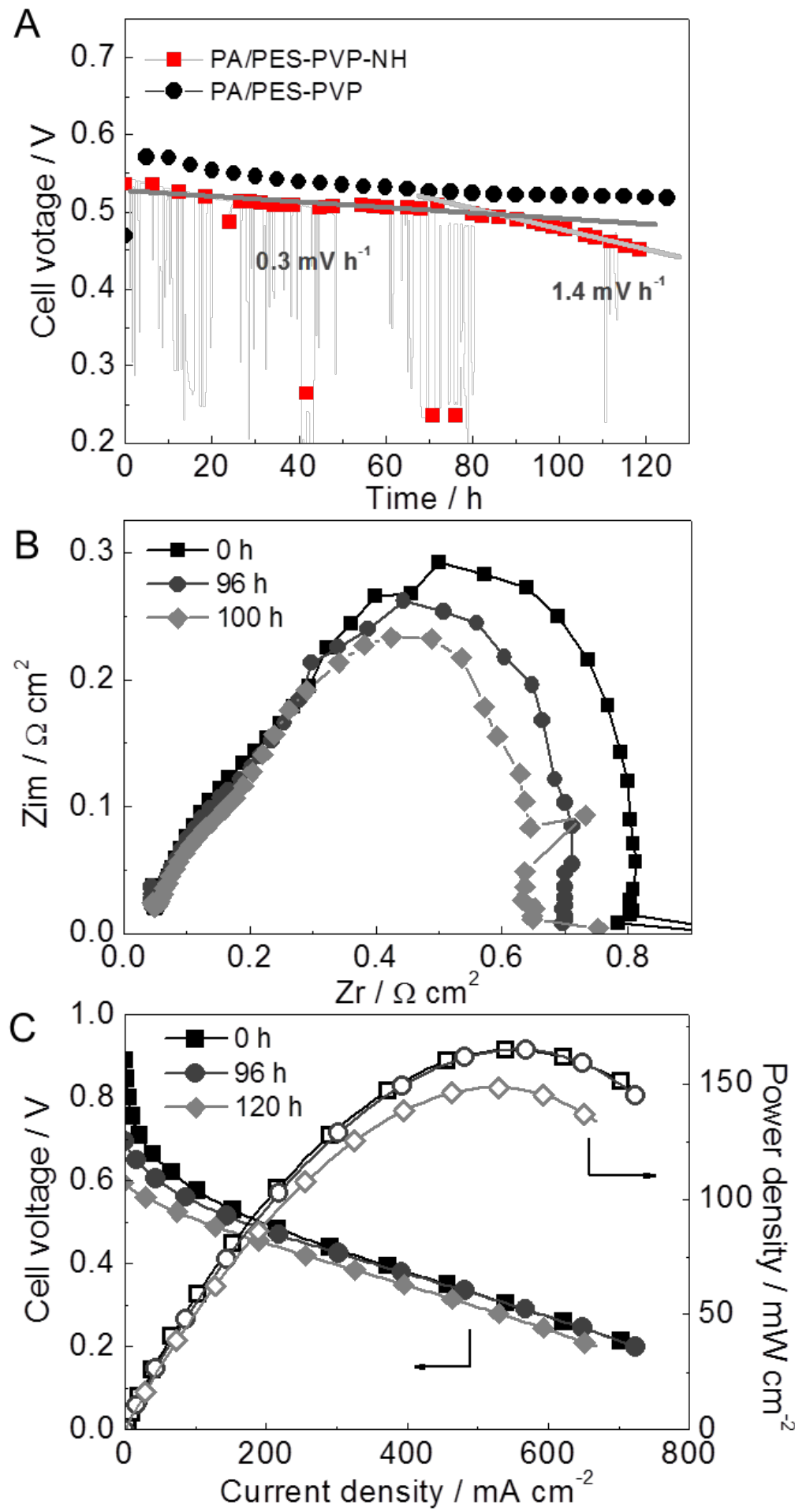

Fig.10 (A) The durability fuel cell performance of with a current load of $200 \mathrm{~mA} \mathrm{~cm}^{-2}$ at 160 ${ }^{\circ} \mathrm{C}$ in $\mathrm{H}_{2} / \mathrm{O}_{2}$ without external humidification. The Pt loading for both the anode and the cathode is $0.26 \mathrm{mg} \mathrm{cm}^{-2}$ for the PA/PES-PVP-NH fuel cell, while it is $0.35 \mathrm{mg} \mathrm{cm}^{-2}$ for the PA/PES-PVP fuel cell. (B) and (C) are the impedance at $0.5 \mathrm{~V}$ and cell performance of the PA/PES-PVP-NH fuel cell at different time. 